\title{
Social Class Index: A New Measurement for Gender Social Stratification
}

\author{
Yao Tang \\ School of Public Administration, Zhejiang University of Finance and Economics, China
}

Copyright $\bigcirc 2017$ by authors, all rights reserved. Authors agree that this article remains permanently open access under the terms of the Creative Commons Attribution License 4.0 International License

\begin{abstract}
This research studied the Chinese gender social stratification by creating the Direct and Indirect 'Social Class Index' (SCI) for each observation. Adopting the Principal Component Analysis, both indices combined many social aspects, such as occupation, ownership, industry, job stability, year of school and hourly earnings etc. In addition, with a changed variable set, which included the occupation concerning information in labour market, and also the household redistribution and exchange impact, a new 'SCI' was formed. This new 'SCI' reconstructed the original social structure and changed the individual's social rank. After comparing the two indices, it was found that the impact of the household in China helped diminish social disparities between couples, genders and social groups. Marital status had a positive effect on the lower social strata and on women.
\end{abstract}

Keywords Social Stratification, Social Class Index, Social Disparities, Gender Issues

\section{Introduction}

There has been extensive discussion about and the measurement of social stratification. In addition, whether family members shared the same social class, and how the household redistribution and exchange impact on the social class of the adult family members has been widely analysed. Class measurement is a complicated procedure and each class measurement has its advantages as well as limitations. The conventional social stratification based on occupation classification is no exception. On the one hand, building the occupation class schema aims to construct a framework that can cluster the population into those with similar circumstances and meanwhile demarcate them from others. Thus, the social structure and the make-up of each social class are clarified. This approach can extract a resemblance for each social stratum and title them, which is also convenient for the study of their universality and tendencies.

However, utilising this method also problematic as the schema is incapable of explaining subtle differences within each social stratum. Occasionally, the social strata have to be sub-classified in order to satisfy the specific research questions. However, these subdivisions can be endless until the subdivision is between each person, because variances between individuals can be constantly identified. At the same time, the variables used for the sub-subdivisions, such as the earnings and education level etc. were combined with occupation in a general and vague way so that they hardly integrated in building the social class schema. On the other hand, the social stratification built on an individual's occupation is based on his or her capacity in the productive sphere. The individual perspective is necessary, especially in the discussion of gender disparities. However, studies merely from an individual perspective imply that one's social stratification is independent, unaffected and mainly relies on one's position in the labour market. This hypothesis hardly exists in reality. As Purcell et al. [1] suggested, the constituted family reshapes an individual's social class through household integration and redistribution. Additionally, household exchange also impacts on the overall social resource distribution and social structure. In the case of exogamous marriages, the social gaps narrow not only in terms of genders, but also the different social strata. Conversely, in endogamous marriages, the social gaps even expand.

Since the individual and household perspective are both essential, how to combine these two perspectives together in the study of social stratification? How is it best to observe the impact of the household? In addition, as differences exist between individuals within the same social stratum, how should these disparities be distinguished? This research tried to construct a 'Social Class Index' (SCI) for each observation to combat these challenges. The function of this index is similar to indices such as the 'Corruption Perception Index' that shows the corruption level in countries, the 'Comprehensive Assessment Index', which expresses the teaching and research capability of universities, and the 'Enterprise Competitive Index' which represents a company's strength and competitiveness in the market. With this 'SCI', each person's exact social position and rank could 
be achieved and compared. Moreover, with a changed variable set, which denoted the household redistribution and exchange, a new 'SCI' was created. By comparing the two indices, the impact of the household on the social stratification of couples, genders, and the overall social stratification could be illuminated.

The structure of this article is as subsequently outlined: Firstly, the procedure of creating the 'SCI' will be discussed. This section includes how the variables were chosen to represent the individual's position in the labour market and how the Principal Component Analysis (PCA) was adopted to form the 'SCI'. Secondly, the article discusses how the other 'SCI', which contained the aspects of household impact, was created. This section will discuss which variables remained and which variables changed and were added to represent the household exchange and redistribution. After determining the variable set, same steps as in forming the 'SCI' was followed. Thirdly, through comparing the two indices and the social ranks based on these two indices, the social disparity changes between couples, genders and social strata can be clarified. Lastly, I conclude why it is essential in the social stratification study to combine the public productive and private redistribution spheres and the individual and household perspectives together.

\section{Construction 'Social Class Index' for Individual}

\subsection{The Factor Choosing Procedure}

This section will first discuss what kinds of occupation characteristics were combined and how to the 'SCI' was created for each observation. Socialists, such as Weber [2], observed the differences between class and social status, and discussed many aspects of social stratification-the performance in the market, for example, in terms of authority, property and particular skills. Later, in order to satisfy the feasibility of empirical class analysis, socialists tried to develop a definite way of detecting discrepancies, such as the methods constructed by John Goldthorpe and his associates [3] [4] [5]. The aim of Goldthorpe's social classification schema was to differentiate positions in labour markets, especially the relations between employers and employees. These relationships can be classified as either 'labour contract' or 'service relationship'. Correspondingly, a range of occupational characteristics, such as conditions of employment, career prospects, and employee autonomy etc. were identified through many specific variables.

This method for the social class classification was a good reference for my research, especially for the process of selecting variables to reflect the characteristics of social class. For example, the degree of occupational security is substituted for a discussion of labour contract status in this study. The 'permanent labour contract' is deemed more stable than the 'odd labour status'. However, realistic issues, such as the datasets limitation should be taken into account. The data used for this research comes from Chinese Household Income Project of 2007. This survey, supported by Chinese Academy of Sciences (CAS), Asian Development Bank (ADB) and Ford Foundation, are designed to estimate the Chinese income distribution. It also provided much information concerning occupation and work situation, as well as other demographic information. However, the dataset did not provide some specific work information, such as the information an employee's autonomy that Goldthorpe suggested. The data contained both surveys of urban and rural population. For occupational classification reasons, this study is strict to the urban population, and the sample observation should satisfy the condition that has job and income. There are 6,777 observations for year 2007.

In the process of selecting variables to give a better picture of social stratification, some basic doctrines were applied. Firstly, the variable of occupation will be included since it is the fundamental component in conventional social stratification. The occupational divisions in the dataset questionnaire were first classified into two main groups: employers and employees. In the case of the employer, they were further divided into the entrepreneur and the self-employed. The entrepreneurs are much higher than the self-employed in terms of their earnings capability or social resources. On the other hand, the employees were divided into non-manual labour and manual labour. The non-manual labourers included the officials and managers ${ }^{\mathrm{i}}$, professionals and clerks, and the manual labour referred to the manual worker and service workers ${ }^{\text {ii }}$.

Secondly, the Chinese characteristics such as the disparities in different kinds of ownership and industry were considered. These two factors intertwine together to determine specific discrepancies in the same occupation stratum in China as Zhou et al. [6] suggested. For example, key industries controlled by government and state owned, such as the finance and banking, were referred to as the state monopoly industry. In contrast, private and individual enterprises have a high percentage in the low-end industries in uncompetitive market sectors, such as restaurant catering and accommodation. According to their position in the state and market sector, the types of industry were divided as follows: state monopoly industry, semi-state monopoly industry, competitive market sector industry, semi-competitive market sector industry and uncompetitive market sector industry. Ownership was generally divided into: state, collective, foreign, private and individual ownership. State ownership not only included state owned enterprises, but also government departments and public institutions.

Thirdly, economic aspects are an essential part of class analysis and were added into the PCA. Discrepancies in employees' economic situation are manifestations and outcomes of disparities in their different occupations, 
ownerships and industries. At the same time, because of 'socio-economic closeness' Erikson et al. [7] suggested, economic circumstances also play an important role in determining the quality of other social aspects. In this study, the information of an individual's earnings was used which was regarded strongly reflects one's financial and economic situation. In addition, attention should be paid to working hours. In the informal market sector, employees' working hours tend to be longer in comparison to the state sector. This is particularly the case in some private enterprises of a small and medium size, where plausible modest earnings are in fact based on employees' overtime work. Therefore, instead of monthly earnings, the variable of hourly earnings was used in synthesizing the 'SCI'.

Fourthly, disparities of social security circumstances, especially social insurance inequality was included. Social insurance system in China does not cover the entirety of society as Hussain [8] suggested. At the same time, the guaranteed degree of support is also different among individuals. According to Saunders et al. [9], the historical urban-rural and ownership part of social insurance system has not been completely eradicated, and is currently related to the financial situation of enterprises and the economic position of employment units .The urban state sectors provide better social insurance for their employees, particularly in the monopoly industries. For those small and medium sized private enterprises, the employers are reluctant to join the insurance scheme due to purposes of cost saving ${ }^{\text {iii }}$. The result is that many employees who work in the informal sector are in an unprotected situation. Social insurance disparities among employees denote their advantaged or disadvantaged position in labour market, which were included in the 'SCI'. The dataset provided information regarding social insurance and house funding, but the exact level was not specified. In this analysis, the employees who had insurance and those who had responsibility for paying the insurance were compared.

Fifthly, information on education was included into the variable set. Education is an important aspect of social stratification. Education, symbolizing the level of human capital, is a starting point for understanding vocational obtainment and career promotion. Education combined with occupation determines economic and social prospects as Bryman [10] suggested. The correlation of educational attainment with employment opportunity, occupation prospects, and earning circumstances demonstrated that education is an important branch of social stratification. In many studies, years of schooling disparities have been used to explain earnings discrepancies. Therefore, in this study, the variable of years of schooling, which represents the level of education, was included in the PCA procedure. The final set concerning different aspects of occupation characteristics was as shown below:

i). Occupation ${ }^{\text {iv }}$ ( 7 for owner of enterprise; 6 for self-employed; 5 for official; 4 for professional; 3 for clerk; 2 for manual labour ; 1 for service worker ); ii). Ownership ${ }^{\mathrm{v}}$ (5 for state ownership; 4 for collective ownership; 3 for foreign ownership; 2 for private ownership; 1 for individual ownership);

iii). Industry ${ }^{\text {vi }}$ ( 5 for state monopoly industry; 4 for semi-state monopoly industry; 3 for competitive market sector industry; 2 for semi-competitive market sector industry; 1 for uncompetitive market sector industry);

iv). Job Stability (5 for permanent worker; 4 for long-contract worker; 3 for short-contract worker; 2 for temporary worker; 1 for domestic helper);

v). Unemployment Insurance ( 5 for paid by employer; 4 for paid by both employer and employee self; 3 for paid by employee self; 2 for no insurance; 1 for do not know the insurance);

vi). Endowment Insurance (5 for paid by employer; 4 for paid by both employer and employee self; 3 for paid by employee self; 2 for no insurance; 1 for do not know the insurance);

vii). Injury Insurance ( 5 for paid by employer; 4 for paid by both employer and employee self; 3 for paid by employee self; 2 for no insurance; 1 for do not know the insurance);

viii). Medical Insurance ( 5 for paid by employer; 4 for paid by both employer and employee self; 3 for paid by employee self; 2 for no insurance; 1 for do not know the insurance);

ix). House Fund ( 5 for paid by employer; 4 for paid by both employer and employee self; 3 for paid by employee self; 2 for no insurance; 1 for do not know the insurance);

$\mathrm{x})$. Year of schooling;

xi). Hourly earnings;

\subsection{The Outcomes from the Principal Component Analysis}

Table 1. The Internal Consistency of the Variables

\begin{tabular}{|c|c|}
\hline Test scale $=$ mean (Standardized items) & \\
\hline Average inter item covariance: & 0.41839 \\
\hline Number of items in the scale: & 11 \\
\hline Scale reliability coefficient: & 0.8878 \\
\hline
\end{tabular}

Source: Chinese Household Income Project, 2007

Note: The 11 standardized items were respectively occupation, ownership, industry, job stability, unemployment insurance, endowment insurance, injury insurance, medical insurance, house fund, years of schooling and hourly earnings.

The PCA result was impacted by the size of the variables. The bigger size of the variable, the more weight arranged onto it. Therefore, in order to eliminate the impact of variables size, each variable was standardized to a $Z$ score at the beginning (zero mean and unit variance of one). In addition, the natural logarithmic forms were employed to reduce skew and linearize relations among the variables. Before taking the PCA, the Cronbach's $\alpha$ (alpha) reliability coefficient was applied to check the internal consistency of the variables. As shown in the table 1, the alpha value was 
0.8878 , which is higher than the requested and acceptable figure 0.7 . This result demonstrates that internal consistency among occupation aspects concerned with social stratification is preferable.

The PCA was used to create the 'SCI'. The PCA is able to convert a set of correlated variables into a set of linearly uncorrelated components, which at the same time represent the connotation of the original variables. The first component explains the maximum amount of variance of the observed variables and can be calculated through the linear combination of these variables. The second component describes the maximum amount of the remaining variance and can be calculated in the same way. The third is so on until all variance is explained. The part of outcomes from PCA is shown in table 2(a) which demonstrated the factor scores that were used to calculate the value of each component. As just mentioned, the principal component value is calculated by multiplying the factor score with the corresponding variable value and then adding the products together. This process can be achieved automatically by STATA.

The other set of outcomes from the PCA is as shown in the table 2(b). The top three components' eigenvalues were higher than 1.0 and together explain approximately $70 \%$ of the cumulative variance of all 11 variables. In this study, all the information of concerned components was used to synthesize the final SCI, even the last component which contributed little in explaining the variance. The proportion of each component is the weight which also presented in the table 2(b). The formula for all the components used in calculating the final 'chief factors fraction' $(F)$ is as shown in the equation (1). With the results from PCA, the value $\mathrm{F}$ in this study can be written as in equation (2).

$$
\begin{gathered}
F=\frac{\lambda_{1}}{\sum_{i=1}^{11} \lambda_{i}} f_{1}+\frac{\lambda_{2}}{\sum_{i=1}^{11} \lambda_{i}} f_{2}+\ldots+\frac{\lambda_{11}}{\sum_{i=1}^{11} \lambda_{i}} f_{11} \\
F=0.4071 f_{1}+0.1801 f_{2}+\ldots+0.0189 f_{11}
\end{gathered}
$$

The value of $\mathrm{F}$ is regarded as representing the ' $\mathrm{SCI}$ ' for each observation after it has been transferred and the maximum is made 100 and the minimum 0 . Thus, each observation has a 'SCI' and the subtle disparities between individuals were demonstrated. Moreover, this 'SCI' consisted of more inclusive occupational information, such as ownership, industry, job stability, social security circumstances, earnings and education level. This synthesized index has many advantages and makes up the defects of the social stratification basing on the occupation classification. However, as mentioned, this index did not consider the redistribution impact in the private household aspect. Later paragraphs will illustrate how the impact from the household was taken into consideration and illuminate in detail how a new 'SCI' was restructured to express it.

\section{The Reconstruction of the 'Social Class Index' for Married Couples}

As discussed in the primary paragraphs, social stratification studies from an individual perspective are necessary, because women are invisible if the household is regarded as a unit and a husband's social status is used to represent his wife's. However, only using an individual approach can exaggerate the gender social gap in terms of social stratification. After all, husbands and wives share many mutual resources and activities during the marriage. Additionally, the household also impacts on the overall social structure when the social position of married couples changes. Furthermore, the social gaps between different social strata can narrow or expand dependent on exogamous or endogamous marriages. In order to observe these issues, a vital task was to determine the impact from the household, especially household redistribution on couples, and then that on the whole population.

The measure of creating an individual 'SCI' through PCA inspired the way to determine the household or marital impact. Household redistribution and exchange can be viewed as an essential dimension to be synthesized into the PCA. Through changing and replacing the original variable set, a new 'SCI' will be created. This index was different from the already created one because this index also included information on shared earnings and consumption in the private household domain. For convenience, the previously discussed index was termed the 'Direct Social Class Index' (DSCI) or 'Direct Index', and the one to be subsequently discussed, was named the 'Indirect Social Class Index' (ISCI) or 'Indirect Index'. The variables, which were incorporated into the PCA for constructing the 'ISCI', are next discussed.

\subsection{Variable Continuities and the Reasons}

Before discussing what variables were selected, one issue must be mentioned. Each variable was standardized first, before putting it into the PCA, and the standardized value was sensitive to the population to which it belonged and changed with the different groups. Therefore, in order to guarantee the comparability of the two 'Social Class Indices', the group or the population needed to come from the same one. There were 6777 observations for creating the 'Direct Index'. The same group was used for forming the 'Indirect Index'. In addition, as the study is concerned with the impact of the household on the social stratification of married couples, the subgroup of married couples was emphasized. These couples were strictly matched in the data to make sure they came from identical households in the two PCA procedures. Of these 6777 observations, there were 2227 married couples (4454 cases), accounting for approximately $66 \%$ of the sample population. 
Table 2(a). Scoring Coefficients from Principal Component Analysis

\begin{tabular}{|c|c|c|c|c|c|c|c|c|c|c|c|c|}
\hline Variable & Comp.1 & Comp.2 & Comp.3 & Comp.4 & Comp.5 & Comp.6 & Comp.7 & Comp. 8 & Comp.9 & Comp.10 & Comp.11 & Unexplained \\
\hline Occupation & 0.3381 & 0.3572 & -0.2688 & 0.1140 & -0.1757 & -0.1205 & 0.3077 & -0.2271 & -0.1968 & 0.0057 & 0.6652 & 0 \\
\hline Ownership & 0.3266 & 0.2672 & -0.2570 & -0.1343 & -0.0026 & -0.1058 & -0.3082 & 0.6560 & 0.4394 & -0.0276 & 0.0865 & 0 \\
\hline Industry & 0.2549 & 0.3391 & 0.0749 & -0.3342 & 0.4930 & 0.6365 & 0.1897 & -0.0925 & -0.0069 & 0.0012 & -0.1000 & 0 \\
\hline Job Stability & 0.3627 & 0.2446 & -0.3266 & 0.0637 & -0.2195 & -0.2180 & 0.1526 & -0.1573 & -0.1587 & -0.0036 & -0.7273 & 0 \\
\hline Endow. Ins. & 0.2749 & -0.4185 & -0.1443 & 0.3443 & 0.3188 & 0.0796 & 0.1586 & 0.4637 & -0.4794 & 0.1782 & 0.0079 & 0 \\
\hline Injury Ins. & 0.3089 & -0.3813 & 0.1235 & -0.2458 & -0.3393 & 0.1084 & 0.2907 & -0.0579 & 0.3482 & 0.5894 & 0.0135 & 0 \\
\hline Unempl. Ins. & 0.3270 & -0.4118 & 0.0359 & -0.0836 & -0.2313 & 0.1852 & 0.1329 & -0.0100 & 0.1001 & -0.7738 & 0.0275 & 0 \\
\hline Medical Ins. & 0.3134 & -0.2147 & -0.0935 & 0.2966 & 0.5236 & -0.2395 & -0.2298 & -0.4610 & 0.4012 & 0.0159 & 0.0297 & 0 \\
\hline House Fund & 0.3387 & -0.0861 & 0.1290 & -0.3137 & -0.1480 & 0.0350 & -0.7000 & -0.1764 & -0.4482 & 0.1082 & 0.0772 & 0 \\
\hline Hourly Earnings & 0.2207 & 0.1219 & 0.6564 & -0.2139 & 0.2112 & -0.5625 & 0.2466 & 0.1431 & -0.0971 & -0.0884 & -0.0151 & 0 \\
\hline Year of Schooling & 0.2070 & 0.2602 & 0.5058 & 0.6596 & -0.2587 & 0.3071 & -0.1418 & 0.0460 & 0.1029 & 0.0384 & -0.0549 & 0 \\
\hline
\end{tabular}

Source: Chinese Household Income Project, 2007

Table 2(b). Principal Components Analysis

\begin{tabular}{|c|c|c|c|c|c|}
\hline & $\begin{array}{l}\text { omponents } / \mathrm{cc} \\
\text { (unrotated }=\mathrm{p}\end{array}$ & & $\begin{array}{l}\text { Number of obs. } \\
\text { Number of comp. } \\
\text { Trace } \\
\text { Rho } \\
\end{array}$ & $\begin{array}{l}= \\
= \\
= \\
=\end{array}$ & $\begin{array}{c}6777 \\
3 \\
12 \\
0.6999 \\
\end{array}$ \\
\hline Component & Eigenvalue & Difference & Proportion & \multicolumn{2}{|c|}{ Cumulative } \\
\hline Component 1 & 4.48402 & 2.712961 & 0.4076 & \multicolumn{2}{|c|}{0.4076} \\
\hline Component 2 & 1.98106 & 1.015558 & 0.1801 & \multicolumn{2}{|c|}{0.5877} \\
\hline Component 3 & 1.23355 & 0.562957 & 0.1121 & \multicolumn{2}{|c|}{0.6999} \\
\hline Component 4 & 0.694549 & 0.0731236 & 0.0631 & \multicolumn{2}{|c|}{0.7630} \\
\hline Component 5 & 0.587453 & 0.0358099 & 0.0534 & \multicolumn{2}{|c|}{0.8164} \\
\hline Component 6 & 0.533692 & 0.0235261 & 0.0485 & \multicolumn{2}{|c|}{0.8649} \\
\hline Component 7 & 0.437845 & 0.024753 & 0.0398 & \multicolumn{2}{|c|}{0.9047} \\
\hline Component 8 & 0.341322 & 0.0151225 & 0.0310 & \multicolumn{2}{|c|}{0.9358} \\
\hline Component 9 & 0.284269 & 0.013438 & 0.0258 & \multicolumn{2}{|c|}{0.9616} \\
\hline Component 10 & 0.214762 & 0.007267 & 0.0195 & \multicolumn{2}{|c|}{0.9811} \\
\hline Component 11 & 0.207473 & & 0.0189 & \multicolumn{2}{|c|}{1} \\
\hline
\end{tabular}

Source: Chinese Household Income Project, 2007 
Now the variable selection used for creating the 'ISCI' will be elaborated. To begin with, the individual's position in the labour market is still the foundation of social class analysis. The social status, as Acker [11] discussed, achieved directly by the individual is different from that attained through attachment with others. In addition, the spouse may have impacted on his or her partner in terms of certain ideas, ideology, consumption tastes, but not their formal interaction with collages, their experiences and activities in their work place etc. occupational characteristics. Furthermore, from a theoretical perspective, even if a partner's occupation was impacted upon, this impact was ultimately reversed by his/ her own occupation and returns us to the old approach to occupational study. From the methodological perspective, this impact from a spouse cannot be measured through the replacement and substitution of the occupational concerned aspects. An attempt to add a new variable of spouse' occupation into the variable set was tried. However, that would lead to losing the observations that were single and undermine the purpose of this research. Therefore, the variables concerned with an individual's occupational position that cannot be shared with spouse were reused to synthesize the 'ISCI'. These variables included: the occupation, ownership, industry, job stability, education level and social insurance circumstances.

\subsection{Variable Changes and the Reasons for Selection}

As the occupation concerned variables remains the same, what variables will be selected to represent the impact of the household? The impact of the household on a married couple's social stratification was supposed to mainly express through shared properties, earnings, economic resources and daily consumption. Firstly, economic resources could be divided, which is different from occupational status, which was hardly shared. In China, economic resource sharing between couples is even guaranteed by law. During marriage, a husband and wife legally and equally claim a joint share in the household. Next, the sharing of household economic resource between the couples is a visible and daily occurrence. This sharing, especially sharing earnings, is the basis for other forms of interaction, and is an essential component of household exchange and redistribution. This tradition in earnings sharing can even be traced back to the period before women went to work and men were regarded as the sole bread earners. Now that women have participated in paid work, their earnings are another contribution to the family.

Consequently, the sharing of economic resources has an important household impact and each partner's individual earnings should be considered integral to the household account after they are married. The data did not provide the total amount of household property, but detailed information about the kinds of household earnings available. This shared household earnings instead of individual earnings, were put to the PCA to present one's impacted economic situation.
Furthermore, household earnings were not only shared between couples, but also included other family members, such as children and elders. So the variable of shared household earnings referred to the total household earning divided by the number of household members. For a single adult living alone, there was no such married household impact, so their individual earnings were still utilised. For married couples, individual earnings were replaced with the shared household earnings for forming the 'ISCI'.

In addition, another three new variables were added, the consumption of food, clothes and culture and entertainment. As mentioned in the above paragraphs, household consumption as shared by family members is an obvious and everyday occurrence. Together with household earnings, this joint consumption behaviour constructed a base for other interactions in the family. Household earnings determined the quality and quantity of household consumption. Consumption in turn represented the household earning circumstances and most importantly it reflected information about a family's living standards and lifestyle through the expenditure portfolio of consumer products. An analysis of repeated everyday mutual consumption and engagement in leisure entertainment activities revealed the impact of the household on individuals. Thus, the information on household consumption that the data provided was included.

Therefore, the variables, which are concerned with the occupation classification, which are hard for couples to share, remained the same. These variables included occupation, ownership, industry, job stability, education level and social security circumstances. As household earnings and consumption conveyed household redistribution and exchange, the variable of individual earnings was replaced with the shared household earnings. Furthermore, another three new variables, consumption on food, clothes, and culture and entertainment, were added in. Following the same steps as when creating the 'DSCI', with the new variable set, each observation was given a new index-the 'ISCI'. Now that the two 'Social Class Indices' have been created, the following section will compare these two indices and perceive how the family impacted on the social stratification of couples, gender and the whole population.

\section{The Impact of the Household on Social Stratification and Gender}

\subsection{Impact on the Overall Social Stratification}

The PCA created the 'Direct Index' and the 'Indirect Index' for each observation. According to their index values, each individual's exact position in the population was ranked. Comparing each observation's two ranks, excepting only two observations, the entire population's social positions readjusted. Among them, approximately $49 \%$ of the population witnessed their social rank rising and 51\% decreased. The inquiry then became whose 'DSCI' declined 
after considering the impact of the household and whose social rank improved? How the ranges of their social class position change? Who improved the most and who the least? In order to answer these questions, the population was divided evenly into ten groups (decile 1-10), according to the individual's 'Direct Index' and 'Indirect Index' respectively. As both of the indices have high and low significance, the groups built on the indices were also equipped with sequence connotation. Decile 1 was supposed to have a highest comprehensive social class position, and social class rank decreased successively from decile 1 to decile 10 .

The composition change in these social groups demonstrated their different change tendency as shown in table 3. Firstly, the upper social group tended to lower their social ranks after readjusting the 'DSCI'. Especially decile 1, the percentage of those whose rank decreased is threefold of the population whose rank increased. On the contrary, the lower social groups, especially decile 10 met an increasing inclination. This phenomenon demonstrated that household exchange and redistribution have an altered impact on different social groups. It tended to lower the upper social groups' original social class position and enhance it for those who came from lower social groups. Household exchange and redistribution bridged the original social gap between individuals of different social groups through reconstructing the social structure.

Next, as to the range of social position changes, the maximum (from the bottom to top) and minimum (from the top to bottom) could take place theoretically. However, in reality, such extreme examples are rare. In addition, the range of improvement and retrogression was diverse for different social groups. As shown in table 3, decile 1 had the smallest range of enhanced social position, because their already high social positions had less room for improvement. For the same reason, decile 10 had the least decline in range. In contrast, the greatest range in change happened in the middle social groups, from decile 3 to decile 7 . Their change in range was even large enough to step out of their original social groups. Moreover, there was a direction difference of change. The lower middle social groups (decile 6 and decile 7) encountered a greater range in terms of enhanced social position. In contrast, the upper middle social groups (decile 3 and decile 4) met a larger range in declined social position. The larger range of the enhanced social position in lower middle social groups and the larger range of the declined social position in upper middle social groups restructured the original middle social groups and relieved the original social gaps between middle groups.

In sum, the 'ISCI' reconstructed the social structure, and changed the individual's social position in the population. From the comparison outcomes of the two individual's social ranks, the top social groups were inclined to lower their original social ranks and the bottom social groups tended to enhance their social positions, although the change in range was not as large as the middle social groups. In addition, the lower middle social groups encountered greater range in terms of their enhanced social position, whereas the upper middle met a larger range in terms of their declined social position. These social position adjustments caused by household impact curtailed the original social gaps between individuals and between different social groups. Can the same statement be concluded for the gender social stratification gaps? The next passages will highlight gender social stratification changes with this 'ISCI' and the ranks.

Table 3. Comparison of Social Class Rank Change

\begin{tabular}{|c|c|c|c|c|c|c|c|c|c|c|}
\hline \multirow{2}{*}{ Comparison } & \multicolumn{2}{|c|}{ Decreased } & \multicolumn{2}{|c|}{ Risen } & \multicolumn{2}{c|}{ Same } & \multicolumn{2}{c|}{ Risen Range } & \multicolumn{2}{c|}{ Decreased Range } \\
\cline { 2 - 12 } & M. & F. & M. & F. & M. & F. & M. & F. & M. & F. \\
\hline Decile1 (Top 10\%) & 76.1 & 63.9 & 23.7 & 36.1 & 0.23 & 0 & 144 & 140 & 365 & 351 \\
\hline Decile2 (T10\%-T20\%) & 65.0 & 57.4 & 35.1 & 42.6 & 0 & 0 & 361 & 429 & 783 & 614 \\
\hline Decile3 (T20\%-T30\%) & 57.6 & 55.9 & 42.4 & 44.2 & 0 & 0 & 542 & 602 & 1021 & 782 \\
\hline Decile4 (T30\%-T40\%) & 58.9 & 48.5 & 41.1 & 51.5 & 0 & 0 & 773 & 918 & 867 & 858 \\
\hline Decile5 (T40\%-T50\%) & 53.8 & 43.5 & 46.3 & 56.5 & 0 & 0 & 862 & 928 & 673 & 815 \\
\hline Decile6 (T50\%-T60\%) & 49.9 & 38.5 & 49.9 & 61.5 & 0.26 & 0 & 915 & 1133 & 685 & 567 \\
\hline Decile7 (T60\%-T70\%) & 50.0 & 39.9 & 50.0 & 60.1 & 0 & 0 & 891 & 889 & 583 & 533 \\
\hline Decile8 (T70\%-T80\%) & 53.0 & 42.5 & 47.0 & 57.5 & 0 & 0 & 641 & 660 & 517 & 477 \\
\hline Decile9 (T80\%-T90\%) & 49.9 & 41.4 & 50.1 & 58.6 & 0 & 0 & 701 & 509 & 372 & 329 \\
\hline Decile10 (Bottom 10\%) & 33.2 & 34.9 & 66.8 & 65.1 & 0 & 0 & 353 & 301 & 146 & 174 \\
\hline Total N. & 2123 & 1350 & 1702 & 1600 & 2 & 0 & 2123 & 1350 & 1702 & 1600 \\
\hline
\end{tabular}

Source: Chinese Household Income Project, 2007.

Note: a. The social groups are divided basing on the 'Direct Social Class Index'.

b. The value of decreased, risen and same from decile1 to decile10 is the percentage of the observations.

c. The range is the median value of each social group.

d. There are together 3,827 cases for men, and 2,950 for women. 
Table 4. The Gender Distribution Change in Social Groups

\begin{tabular}{|c|c|c|c|c|c|c|c|}
\hline \multirow{2}{*}{ Comparison } & \multicolumn{3}{|c|}{ 'Direct Social Class Index' } & \multicolumn{3}{|c|}{ 'Indirect Social Class Index' } & \multirow{2}{*}{ Total N. } \\
\hline & М. & F. & M. $/ \mathbf{F}$. & M. & F. & M. $/$ F. & \\
\hline Decile1 (Top 10\%) & 11.3 & 8.3 & 1.36 & 10.4 & 9.4 & 1.11 & 675 \\
\hline Decile2 (T10\%-T20\%) & 10.7 & 9.2 & 1.17 & 10 & 10 & 1.01 & 678 \\
\hline Decile3 (T20\%-T30\%) & 10.8 & 9 & 1.2 & 10.4 & 9.5 & 1.1 & 678 \\
\hline Decile4 (T30\%-T40\%) & 10.9 & 8.9 & 1.22 & 10.6 & 9.3 & 1.14 & 678 \\
\hline Decile5 (T40\%-T50\%) & 10.5 & 9.4 & 1.11 & 10.4 & 9.5 & 1.1 & 678 \\
\hline Decile6 (T50\%-T60\%) & 9.9 & 10.1 & 0.98 & 9.8 & 10.3 & 0.95 & 678 \\
\hline Decile7 (T60\%-T70\%) & 8.9 & 11.4 & 0.78 & 10.2 & 9.7 & 1.06 & 678 \\
\hline Decile8 (T70\%-T80\%) & 9.2 & 11 & 0.84 & 9.6 & 10.5 & 0.92 & 678 \\
\hline Decile9 (T80\%-T90\%) & 9 & 11.3 & 0.8 & 9.2 & 11.1 & 0.83 & 678 \\
\hline Decile10 (Bottom 10\%) & 8.9 & 11.5 & 0.77 & 9.3 & 10.9 & 0.86 & 678 \\
\hline Total & 3,827 & 2,950 & 1.3 & 3,827 & 2,950 & 1.3 & 6,777 \\
\hline
\end{tabular}

Source: Chinese Household Income Project, 2007.

Note: The Value from Top $10 \%$ to Bottom $10 \%$ is the Percentage of the Observations.

\subsection{Impact on Gender Social Stratification}

To begin with, the social stratification based on DSCI is not optimistic for women. As shown in table 4, large portion of women gathered in the lower half social groups. However, after the reconstructing by ISCI, even though men still had advantages in terms of social stratification, the gender ratio gaps was much decreased. The share of women augmented in the upper half of the social groups and declined in the lower half. In contrast, the percentage of men increased in the lower half and increased in the upper half. This balancing gender ratio changes demonstrated the positive household impact on women and its role in relieving the gender social gaps. The other evidence came from the gender comparison of two social ranks change. In the table $3,55.5 \%$ of men declined their social class ranks, whereas there was a $45.8 \%$ decline for women. For those who increased their social class ranks, the situation happened in reverse. More women $(54.2 \%)$ witnessed their social class ranks increase, which were $10 \%$ higher than that of men.

Next, regarding the range of social class position change, it was different for men and women. Table 3 also demonstrated the gender comparisons of range change in different social groups. For those who upgraded their social positions, women had a tendency to improve much more than men. Especially for decile 5, women had both a larger proportion and range of enhancement in their social positions. In contrast, for those who regressed, women were inclined to descend to a lesser extent. All these evidences, such as the comparison of each observation's two ranks, the balanced gender ratio in the social groups and the unbalanced change in range of the social ranks proved that household impact was beneficial on a woman's social stratification and relieved the original gender social gap.

This conclusion verified the necessity of the household impact study on gender social stratification. At the same time, it also confirmed Goldthorpe's conclusion that only using the individual perspective, and not considering the impact of the household on married couples, artificially enlarged the gender gaps. Now it is known the impact of household curtailed the social gap among different social groups and genders. Why and how marriage made it? The reasons will be explored next.

\section{Marital Choices and its Impact on Couples' Social Stratification}

In order to clarify how 'ISCI' played a part in relieving the social gaps between genders and different social groups, discussion should begin with the model of marital choice in terms of the spouse' social stratification. After strictly matching the information on married couples in the identical households, the comparison of the 'DSCI' between couples demonstrated that a husband usually had a higher 'Direct Index' than his spouse before they got married. As shown in table $5,62 \%$ of husband's social position was higher than their wives, which was twice that of the proportion of wives, whose 'DSCI' was higher than their husbands. The gender social gap between husband and wife in the productive domain faced a restructuring after they married and it was this restructuring that diminished the social gaps in genders and in social groups. 
Table 5. Comparison the Direct and Indirect 'Social Class Index' Between Couples

\begin{tabular}{|c|c|c|c|c|c|c|}
\hline \multirow{2}{*}{ 'Direct Social Class Index' } & \multicolumn{2}{|c|}{ Male } & \multicolumn{2}{|c|}{ Female } & \multicolumn{2}{|c|}{ Total } \\
\hline & $\mathbf{N}$. & $\%$ & N. & $\%$ & $\mathbf{N}$. & $\%$ \\
\hline Higher than Partner & 1,347 & 62.0 & 758 & 34.9 & 2,105 & 48.4 \\
\hline Equal as Partner & 68 & 3.1 & 68 & 3.1 & 136 & 3.1 \\
\hline Lower than Partner & 758 & 34.9 & 1,347 & 62.0 & 2,105 & 48.4 \\
\hline Total & 2,173 & 100 & 2,173 & 100 & 4,346 & 100 \\
\hline \multirow{2}{*}{ 'Indirect Social Class Index' } & \multicolumn{2}{|c|}{ Male } & \multicolumn{2}{|c|}{ Female } & \multicolumn{2}{|c|}{ Total } \\
\hline & N. & $\%$ & N. & $\%$ & $\mathbf{N}$. & $\%$ \\
\hline Higher than Partner & 1,166 & 53.7 & 768 & 35.3 & 1934 & 44.5 \\
\hline Equal as Partner & 239 & 11.0 & 239 & 11.0 & 478 & 11.0 \\
\hline Lower than Partner & 768 & 35.3 & 1,166 & 53.7 & 1,934 & 44.5 \\
\hline Total & 2,173 & 100 & 2,173 & 100 & 4,346 & 100 \\
\hline
\end{tabular}

Source: Chinese Household Income Project, 2007.

Actually, the original gender social gaps between couples were relieved, no matter whether the husband's social position was higher, or lower than his wife. This was because their social gaps were averaged through the household shared economic resources and consumption when the related variables were putting into the PCA. This average result was represented in the way that a husband's 'Indirect Index' decreased if it was higher than his wife at the beginning. It could also improve if it was lower originally. The improvement in a husband's social position, even if the portion was not as much as wives', was another form of gender social gap decline. A husband's enhanced social position reduced the original social gaps with his wife who had a higher 'DSCI'. Correspondingly, a wife met an improvement in her social position if hers was lower than her counterpart. As the proportion of wives, whose original social positions were lower than husbands, was larger, the enhanced effect was more significant for wives. Therefore, as long as there was a difference between couples in the productive sphere, the impact of the household was going to average it and the gender social gaps decreased.

The household averaging impact reduced the social gaps between couples and the genders. However, if the social gaps between couples mainly happened in the same social group level, the social gaps between different households could be enlarged due to this high possibility of endogamy. If most men from the higher social groups married women also from the higher social groups, even with the household averaging impact reducing the gender social gap, the social gaps between different families, different social groups could expand. In order to provide a specific picture of Chinese marriage matching and the social gaps between couples, a comparison of their belonging to social groups was delivered in the table 6 .
On the one hand, the highest proposition of marriage happened in the same social groups. However, excepting decile 1 and 10, the share of the same-social-group marriage was less than half, and less than the total percentage of cross-social-group marriage. Cross-social-group marriage (exogamy) decreased the original social gaps between different households, and then the different social groups. In addition, closer to the middle social group, this exogamy was more significant. Its explanation is similar to the clarification of the household impact on the overall social groups that the population in the middle social group had more chances for mobility. Exogamy was slim for decile 1 and decile 10 . Upward exogamy for the top is hard because they cannot rise higher, and the same applies in the opposite direction downward for the bottom social group.

On the other hand, compared with men, woman engaged in more cross-social-group marriage, especially upward exogamy. Still as shown in table 6, the cases in the upper right hand for women who married higher than their own social class - were much more than the lower left hand. Men coming from the lower half of the social groups scarcely married the women in the upper half. On the contrary, this percentage was much higher for women. That women managed to marry men in higher social groups not only decreased the social gaps between genders, but also the gaps between different social groups. Therefore, marriage, especially the cross class marriage, objectively played a role in reallocation and redistribution of the social resources and bridging the social gaps between different social groups and genders. There is hypothesis that in a polarizing society, for example like China whose Gini coefficient increased fast, the endogamy will increase which aggravate the already severe social gap between different groups. This comparison would be worth to study in the future. 
Table 6. The Affiliated Social Groups Comparison between Couples based on 'DSCI' and 'ISCI'

\begin{tabular}{|c|c|c|c|c|c|c|c|c|c|c|c|}
\hline $\begin{array}{c}\text { Wife } \\
\text { Husband } \\
\end{array}$ & D.1 & D.2 & D.3 & D.4 & D.5 & D.6 & D.7 & D.8 & D.9 & D.10 & Total \\
\hline Decile1 (Top 10\%) & 120 & 46 & 22 & 25 & 15 & 23 & 15 & 10 & 6 & 2 & 284 \\
\hline Decile2 (T10\%-T20\%) & 28 & 63 & 47 & 24 & 16 & 17 & 26 & 13 & 11 & 8 & 253 \\
\hline Decile3 (T20\%-T30\%) & 17 & 22 & 59 & 28 & 26 & 31 & 19 & 20 & 7 & 4 & 233 \\
\hline Decile4 (T30\%-T40\%) & 8 & 20 & 30 & 41 & 36 & 26 & 30 & 16 & 22 & 12 & 241 \\
\hline Decile5 (T40\%-T50\%) & 8 & 8 & 17 & 33 & 47 & 36 & 32 & 23 & 22 & 14 & 240 \\
\hline Decile6 (T50\%-T60\%) & 4 & 8 & 6 & 16 & 24 & 36 & 48 & 26 & 17 & 14 & 199 \\
\hline Decile7 (T60\%-T70\%) & 2 & 7 & 7 & 8 & 20 & 22 & 42 & 33 & 23 & 13 & 177 \\
\hline Decile8 (T70\%-T80\%) & 0 & 3 & 4 & 5 & 14 & 15 & 27 & 41 & 36 & 20 & 165 \\
\hline Decile9 (T80\%-T90\%) & 2 & 2 & 2 & 8 & 8 & 8 & 17 & 28 & 66 & 45 & 186 \\
\hline Decile10 (Bottom 10\%) & 1 & 6 & 1 & 1 & 4 & 3 & 6 & 16 & 29 & 128 & 195 \\
\hline Total & 190 & 185 & 195 & 189 & 210 & 217 & 262 & 226 & 239 & 260 & 2,173 \\
\hline $\begin{array}{c}\text { Wife } \\
\text { Husband } \\
\end{array}$ & D.1 & D.2 & D.3 & D.4 & D.5 & D.6 & D.7 & D.8 & D.9 & D.10 & Total \\
\hline Decile1 (Top 10\%) & 149 & 52 & 15 & 7 & 7 & 9 & 7 & 3 & 1 & 0 & 250 \\
\hline Decile2 (T10\%-T20\%) & 22 & 103 & 38 & 18 & 12 & 6 & 8 & 9 & 8 & 0 & 224 \\
\hline Decile3 (T20\%-T30\%) & 8 & 29 & 74 & 52 & 19 & 10 & 8 & 15 & 13 & 3 & 231 \\
\hline Decile4 (T30\%-T40\%) & 5 & 12 & 33 & 64 & 44 & 31 & 15 & 15 & 12 & 3 & 234 \\
\hline Decile5 (T40\%-T50\%) & 4 & 4 & 14 & 34 & 76 & 43 & 29 & 21 & 20 & 7 & 252 \\
\hline Decile6 (T50\%-T60\%) & 1 & 8 & 10 & 11 & 31 & 70 & 42 & 24 & 11 & 13 & 221 \\
\hline Decile7 (T60\%-T70\%) & 5 & 4 & 6 & 8 & 13 & 24 & 70 & 40 & 23 & 13 & 206 \\
\hline Decile8 (T70\%-T80\%) & 2 & 4 & 7 & 10 & 12 & 14 & 24 & 69 & 35 & 17 & 194 \\
\hline Decile9 (T80\%-T90\%) & 2 & 1 & 3 & 6 & 5 & 13 & 9 & 27 & 79 & 33 & 178 \\
\hline Decile10 (Bottom 10\%) & 0 & 0 & 0 & 1 & 2 & 4 & 4 & 9 & 27 & 136 & 183 \\
\hline Total & 198 & 217 & 200 & 211 & 221 & 224 & 216 & 232 & 229 & 225 & 2,173 \\
\hline
\end{tabular}

Source: Chinese Household Income Project, 2007.

Note: The First Part of the Table is based on the 'Direct Social Class Index', and the Second Part is based on the 'Indirect Social Class Index'.

\section{Conclusions}

This article developed a new method to study gender social stratification. Through the PCA, a comprehensive DSCI for each observation was created. This index combined many aspects of social stratification and can express subtle differences between individuals even in the same social stratum. The way to study the 'SCI' enlightened how to study the impact of the household on married couples. Some features related to the position in the labour market that were hardly shared with spouses remained the same. Other aspects concerned with the household shared consumptions were added in. In addition, the shared household earnings replaced the individual's earnings. With this changed variable set, the ISCI which expressed the impact of the household was achieved.

The 'ISCI' reconstructed the original social structure and changed the individual's social position in the population. After comparing the component change of different social groups, it was found that the social disparities between couples, genders and social groups were diminished. Marital status may have a negative impact on women in the labour market, but it had a positive effect through shared household economic resources and consumption. Gender social stratification analysis without reference to the impact of the household can artificially expand the gender issues and the social gaps between different social groups. This readjusted 'ISCI' provided a more comprehensive assessment, which made up for the shortcoming of the studies only from the individual or the household perceptive.

\section{REFERENCES}

[1] Purcell, David, Kelly R. MacArthur, and Sarah Samblanet. 2010. "Gender and the Glass Ceiling At Work." Sociology Compass No. 4 (9):705-717.

[2] Weber, Max. 1946. "Class, Status, Party." PP.180-95 in From Max Weber: Essays in Sociology edited by Max Weber: Oxford University Press.

[3] Goldthorpe, John H. 1980. Social Mobility and Class Structure in Modern Britain. Oxford: Clarendon Press.

[4] Goldthorpe, John H. 2007. On Sociology 1, Critique and Program. Stanford, Calif.: Stanford Univ. Press. 
[5] Erikson, Robert, John H. Goldthorpe, and Lucienne Portocarero. 1979. Intergenerational Class Mobility In Three Western European Countries. Stockholm: Almquist \& Wiksell Intern.

[6] Zhou, Xueguang, Nancy B. Tuma, and Phyllis Moen. 1995. Stratification Dynamics under State Socialism: The Case Of Urban China, 1949-1993: Cornell University.

[7] Erikson, R., John. H. Goldthorpe, and M. Hallsten. 2012. "No Way Back Up From Ratcheting Down?

[8] Hussain, Athar. 1994. "Social Security in Present-Day China and Its Reform." The American Economic Review No. 84 (2):276-280.

[9] Saunders, Peter, and Xiaoyuan Shang 2001. "Social Security Reform in China's Transition to a Market Economy." Social Policy \& Administration 35(3): 274-89.

[10] Bryman, Alan. 2012. Social Research Methods. Oxford University Press.

[11] Acker, Joan. 1973. "Women and Social Stratification: A Case of Intellectual Sexism." American Journal of Sociology: 936-945.

i The value principle of 'official rank standard' is still phenomenal in China Therefore, the social status of the officials and the managers (especially the managers in the state-owned enterprises) is higher than the professionals in China.

ii Here the service worker refers to those who provide services to other people, including receptionists, shop assistants, waiters etc.

iii According to the labour law, medical, endowment and unemployment insurance are shared by the enterprises and employees, whereas injury and maternity insurance are the complete responsibility of the enterprises.

iv 56 Occupation, ownership and industry are conceived as quasi-metric variables here. 